\title{
Improvement of fuel qualities of solid fuel biochars by washing treatment
}

\author{
Zhengang Liu ${ }^{\text {a,* }}$, S. Kent Hoekman ${ }^{\text {b }}$, Rajasekhar Balasubramanian ${ }^{\text {c }}$, Fu-Shen Zhang ${ }^{\text {a }}$ \\ a Research Center for Eco-Environmental Sciences, Chinese Academy of Sciences, Beijing 100085, China \\ b Division of Atmospheric Sciences, Desert Research Institute (DRI), 2215 Raggio Parkway, Reno, NV 89512, USA \\ c Department of Civil and Environmental Engineering, National University of Singapore, Singapore 117576, Singapore
}

\section{A R T I C L E I N F O}

\section{Article history:}

Received 16 September 2014

Received in revised form 20 January 2015

Accepted 22 January 2015

Available online 7 February 2015

\section{Keywords:}

Pollutant emission

Fuel quality

Combustion

Ash-related problem

\begin{abstract}
A B S T R A C T
Raw biomass washing prior to pyrolysis treatment has been employed to mitigate the ash-related problems encountered during resultant biochar combustion. However, wide-spread application of this approach is limited by high energy consumption and low washing efficiency. In the present study, the biochar washing instead of raw biomass washing was attempted to overcome aforementioned problems, and fuel qualities of washed biochars were investigated for the first time. The results showed that major ash forming metals can be efficiently removed by all tested washing agents (de-ionized water (DW), acetic acid (AA) and citric acid (CA)), especially for acid washing agents $\mathrm{AA}$ and CA. As a consequence, the ash content of the biochars decreased, and the slagging and fouling issues were dramatically mitigated. Due to metal removal, the washed biochars exhibited improved combustion properties, especially for the biochars derived from agricultural biomass. In addition, noticeable decreases in nitrogen and sulfur contents were observed following washing treatment, suggesting the additional benefit of reducing emissions of nitrogen and sulfur pollutants during washed biochar combustion.

Compared to raw biomass washing prior to pyrolysis, the significantly increased washing efficiency and fuel quality and decreased hydrophilicity of the biochars indicate that pyrolysis combined with subsequent biochar washing is more suitable to produce solid fuel biochars with high fuel quality from different source of waste biomass.
\end{abstract}

(c) 2015 Elsevier B.V. All rights reserved.

\section{Introduction}

Biomass is increasingly regarded as a promising renewable feedstock for the production of heat, chemicals and power due to the global warming situation and environmental pollution caused by the excessive use of fossil fuel worldwide [1-3]. Among various utilization methods, co-combustion of biomass with coal in existing coal-fired power plants has been carried out over the years and is considered to be the lowest risk, least expensive and most efficient strategy of combining utilization of biomass energy with substantial reduction of air pollutants $\left(\mathrm{CO}_{2}, \mathrm{NO}_{\mathrm{x}}\right.$, $\mathrm{CO}$ and $\mathrm{SO}_{2}$ ). However, the extensive studies related to biomass and coal co-combustion have identified several technical constraints [4]. For example, high content of alkali and alkaline earth metals (AAEMs) originally contained in raw biomass can cause serious slagging and fouling problems on boiler heat transfer surfaces during biomass and coal co-combustion. In addition, the disposal of mixed ash is one of the key concerns because the nature of mixed ash is very different from that of coal ash, especially when high raw biomass/coal ratios are used. As for thermal efficiency, raw biomass and coal are just physically mixed together during co-combustion due to their different

\footnotetext{
* Corresponding author. Tel./fax: + 861062912718.

E-mail address: zgliu@rcees.ac.cn (Z. Liu).
}

combustion behaviors and there is no interaction between raw biomass and coal, resulting in low thermal efficiency of co-combustion systems [4]. In the case of fuel preparing, wide diversity of physical shapes, densities among different source of biomass feedstocks coupled with poor grindability creates significant challenges in handling and feeding blend fuels into process units. All these constraints are originated from the great differences in fuel properties between raw biomass and coal. Therefore, a pretreatment process prior to combustion is required, in which biomass is converted into a form similar to coal, thereby reducing the aforementioned problems.

Low temperature pyrolysis is one of the principal thermochemical approaches for biomass upgrading and the resultant biochars have improved fuel quality compared to raw biomass such as significantly enhanced grindability and energy density $[5,6]$. For example, some biochars have energy density similar to lignite and obvious synergistic interactions were observed between biochars and lignite during co-combustion, resulting in increased thermal efficiency and environmental benefits $[7,8]$. However, ash-related problems encountered during raw biomass combustion are still present and even become more serious during biochar combustion because all the inorganic compounds originally in raw biomass are accumulated in the biochars $[7,9]$. In consequence, pre-treatment is necessary to remove those accumulated troublesome elements from the biochars prior to combustion. 
Several studies have been conducted on removing the inherent metals from raw biomass by washing treatment [10-16]. Some metals, such as $\mathrm{K}$ and $\mathrm{Na}$, are reported to be removed from raw biomass by water washing; however, the washing means high energy consumption during drying process due to high hydrophilic property of raw biomass [17]. Moreover, some reported washing agents contain nitrogen, chlorine and sulfur elements, and the residual washing agents in the fuel also pose a potential danger for the environment [15]. Compared to raw biomass, the biochars have decreased hydrophilicity $[17,18]$. Therefore, the biochar washing is more suitable than raw biomass washing, which involves less energy consumed during drying process after washing treatment. As for the washing agent, acetic acid (AA) and citric acid (CA) can be produced from biomass feedstocks, and their residuals have no negative environmental influence, having high potential to serve as washing agent to achieve maximum environmental benefits.

To the best our knowledge, very little information about biochar washing is available $[14,19]$. In the present study, washing treatments were employed for the first time to mitigate the ash-related problems of biochars derived from agricultural and woody biomass. Besides de-ionized water (DW), two green chemicals, acetic acid (AA) and citric acid (CA) were used as washing agents. The removal efficiencies of major ash forming metals by different washing agents were investigated systematically. In addition, the combustion behaviors of washed biochars were determined to investigate the effect of washing treatment on the thermal efficiency of biochar combustion.

\section{Materials and methods}

\subsection{Materials}

Pinewood (PW) and coconut fiber (CF) were selected as representative woody and agricultural biomass for biochar production, respectively. The biochars were produced at $350{ }^{\circ} \mathrm{C}$ and the detailed preparation procedure was reported elsewhere [7]. The biochars derived from PW and CF were labeled as PPW and PCF, respectively. Table 1 shows the properties of the biochars PPW and PCF used in the present study.

\subsection{Washing treatment}

The biochar sample was soaked with the washing agent (DW, $0.5 \mathrm{~mol} / \mathrm{L} \mathrm{AA}$ and CA) in a closed beaker (biochar/washing agent $=1 / 50(\mathrm{~g} / \mathrm{ml}))$ and then the mixture was stirred at $250 \mathrm{rpm}$ for

Table 1

Properties of pyrolytic biochars used in the present study.

\begin{tabular}{lrl}
\hline Fuel & PCF & PPW \\
\hline Ultimate analysis (dry ash free, wt.\%) & & \\
$\mathrm{C}$ & 67.51 & 76.00 \\
$\mathrm{H}$ & 3.95 & 4.65 \\
$\mathrm{~N}$ & 1.01 & 1.40 \\
$\mathrm{~S}$ & 0.37 & 0.34 \\
O (by difference) & 27.16 & 17.61 \\
Proximate analysis (dry base, wt.\%) & & \\
Volatile matter & 30.02 & 34.32 \\
Fixed carbon & 60.81 & 63.46 \\
Ash & 9.18 & 2.23 \\
& & \\
Major ash forming metal analysis & & \\
(dry base, wt.\%) & & \\
$\mathrm{K}$ & 3.331 & 0.179 \\
Ca & 0.689 & 0.340 \\
$\mathrm{Na}$ & 0.245 & 0.021 \\
$\mathrm{Mg}$ & 0.124 & 0.054 \\
$\mathrm{Fe}$ & 0.037 & 0.093 \\
$\mathrm{Al}$ & 0.012 & 0.033 \\
$\mathrm{Ti}$ & 0.016 & - \\
$\mathrm{Si}$ & 0.049 & 0.110 \\
\hline
\end{tabular}

10 min at room temperature $[15,20]$. Subsequently, the washed biochars were recovered by centrifuge and dried at $105^{\circ} \mathrm{C}$ for $24 \mathrm{~h}$ for later analysis. The washed biochars from PCF and PPW are labeled as PCF-Xx and PPW-Xx, respectively, where "Xx" shows the washing agent. For example, PCF-DW refers to the biochar PCF washed by DW. All the washing experiments were performed repeatedly to ensure the reliability.

\subsection{Characterization}

The carbon, hydrogen, nitrogen and sulfur contents were determined on an EA3000 Elemental Analyzer (Italy). The fuel ash was prepared at $575{ }^{\circ} \mathrm{C}$ according to standard test method for ash in biomass (ASTM D 1102). The contents of major ash forming metals in the biochar/ash were determined by digestion method. The biochar/ash was digested in mixed solutions ( $2 \mathrm{ml} 65 \% \mathrm{HNO}_{3}, 2 \mathrm{ml} \mathrm{30 \%} \mathrm{H}_{2} \mathrm{O}_{2}$ and $0.5 \mathrm{ml} 48 \% \mathrm{HF}$ ) at $180{ }^{\circ} \mathrm{C}$ for $30 \mathrm{~min}$ in a Hanon microwave digester (China). The digestion solution was then evaporated to dryness to remove the fluorides and the resultant residues were dissolved in 1:1 $\mathrm{HNO}_{3}$ solutions, followed by dilution with de-ionized water to desired volume. Subsequently, metal concentrations ( $\mathrm{K}, \mathrm{Na}, \mathrm{Ca}, \mathrm{Fe}, \mathrm{Si}, \mathrm{Al}, \mathrm{Ti}$ and $\mathrm{Mg}$ ) in the digestion solutions were quantified using ICP-OES (Perkin Elmer 3000DV, USA). The metal oxide content was calculated according to corresponding metal content in ash. The removal rate of each specific metal from the biochar was calculated as shown below in the equation:

Removal rate $=\left(1-\frac{\text { Metal content in washed biochar }}{\text { Metal content in raw biochar }}\right) \times 100 \%$

The fouling, slagging and slag viscosity indices with the use of the biochars were investigated and the corresponding definition and limits were shown in Table $2[7,21]$.

\subsection{Combustion analysis}

A thermobalance TGA-7 (Perkin Elmer, USA) was used for the combustion experiments. All combustion experiments were conducted at atmospheric pressure, using temperatures ranging from room temperature to $650{ }^{\circ} \mathrm{C}$ with a heating rate of $20^{\circ} \mathrm{C} / \mathrm{min}$ and an air flux of $50 \mathrm{ml} / \mathrm{min}[7,9]$. To minimize the effects of mass and heat transfer limitations, small amounts of biomass samples (around $6 \mathrm{mg}$ ) were loaded into an alumina crucible. Three replicates of each TGA experiment were performed to determine the reproducibility.

Table 2

The definition and limits of slagging, fouling and slag viscosity indices.

\begin{tabular}{lll}
\hline & Expression & Limit \\
\hline Slagging index & $\mathrm{SI}=(\mathrm{B} / \mathrm{A}) \times \mathrm{S} \%$ & $\mathrm{SI}<0.6$ low slagging \\
& & inclination \\
& & $0.6<\mathrm{SI}<2.0$ medium \\
& & $2.0<\mathrm{SI}<2.6$ high \\
& & $\mathrm{SI} \geq 2.6$ extremely high \\
Fouling index & $\mathrm{FI}=(\mathrm{B} / \mathrm{A}) \times\left(\mathrm{Na}_{2} \mathrm{O}+\mathrm{K}_{2} \mathrm{O}\right)$ & $\mathrm{FI} \leq 0.6$ low fouling \\
& & inclination \\
& & $0.6<\mathrm{FI}<40$ medium \\
& & $\mathrm{FI} \geq 40$ high \\
Slag viscosity & $\mathrm{SVI}=\left(\mathrm{SiO}_{2} \times 100\right) /\left(\mathrm{SiO}_{2}+\mathrm{MgO}+\right.$ & $\mathrm{IV}>72$ low slagging \\
index & $\left.\mathrm{CaO}+\mathrm{Fe}_{2} \mathrm{O}_{3}\right)$ & inclination \\
& & $65 \leq \mathrm{IV} \leq 72$ moderate \\
& & $\mathrm{IV}<65$ high \\
\hline Base- to-acid ratio: $\mathrm{B} / \mathrm{A}=\left(\mathrm{K}_{2} \mathrm{O}+\mathrm{CaO}+\mathrm{Na}_{2} \mathrm{O}+\mathrm{MgO}+\mathrm{Fe}_{2} \mathrm{O}_{3}\right) /\left(\mathrm{SiO}_{2}+\mathrm{TiO}_{2}+\mathrm{Al}_{2} \mathrm{O}_{3}\right)$
\end{tabular}




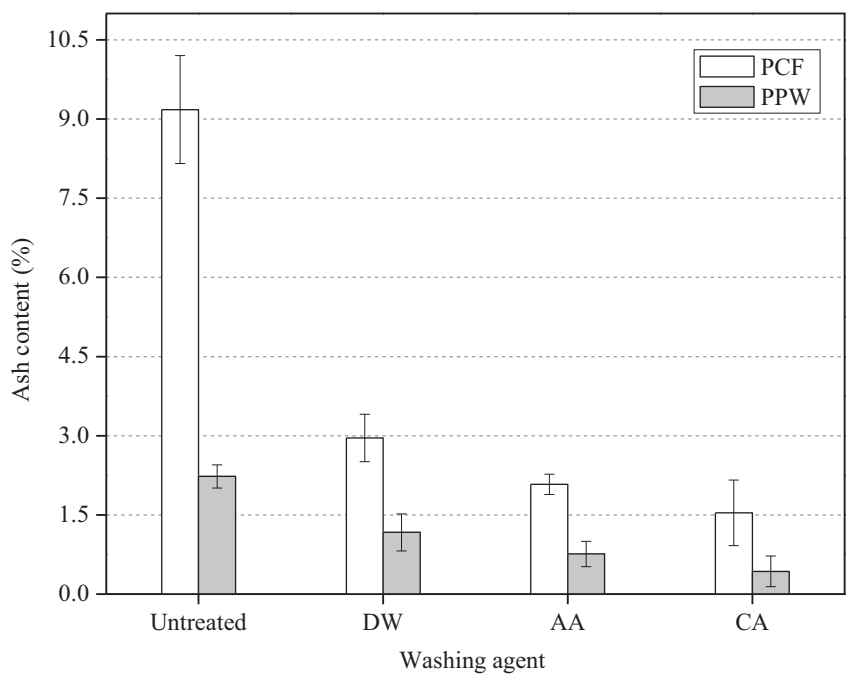

Fig. 1. Ash contents of the untreated and washed biochars.

\section{Results and discussion}

\subsection{Ash content}

Fig. 1 shows the ash contents of the untreated and washed biochars. It is clear that the washed biochars have decreased ash compared to the
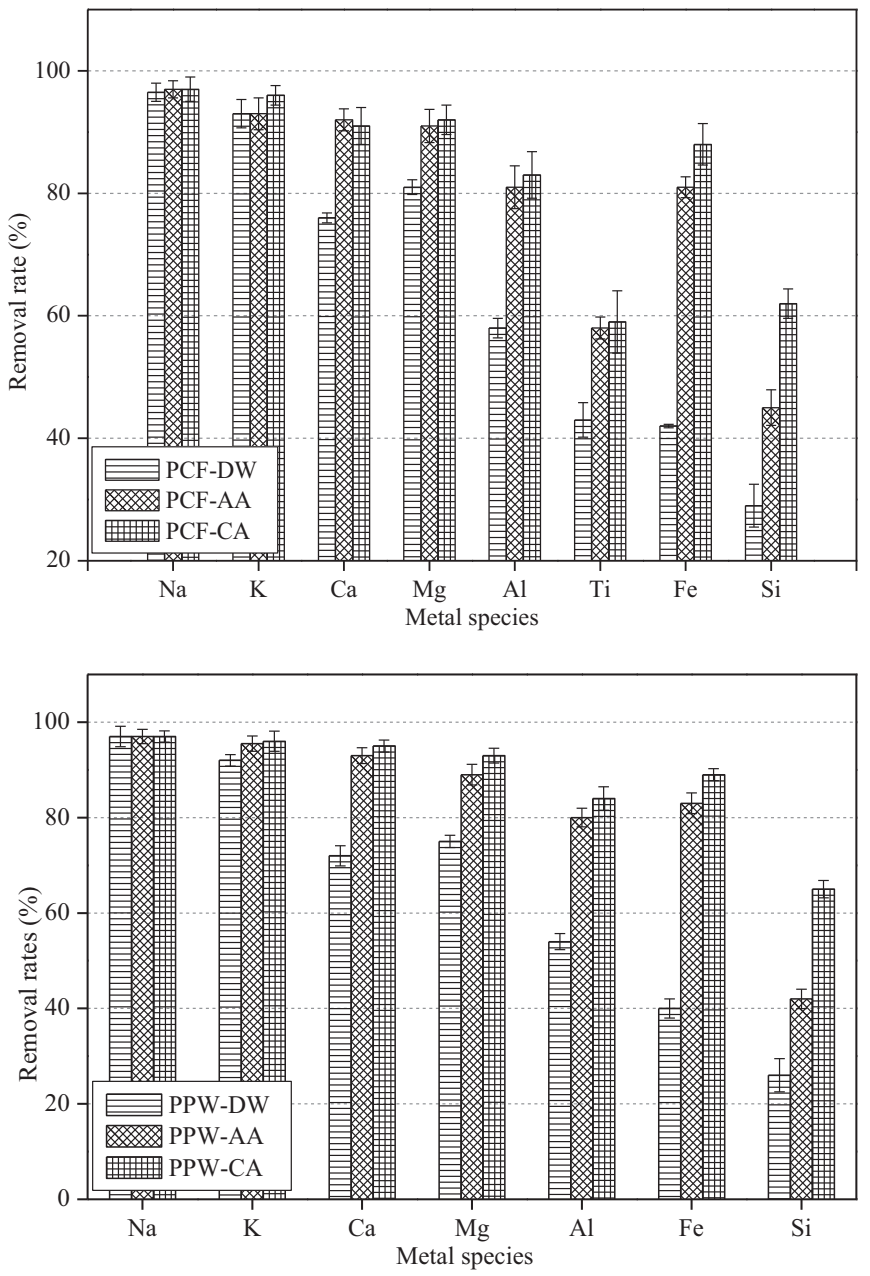

Fig. 2. Removal rates of major ash forming metals from the biochars by different washing agents. untreated biochars, and that among the tested washing agents, CA has the highest potential to reduce ash content of the biochars (the ash content of PCF-CA and PPW-CA are 1.54 and $0.43 \%$, respectively). The decreased ash content will reduce the cost of ash removal from furnaces and facilitate the ash disposal after biochar combustion.

\subsection{Major ash forming metals}

Removal of major ash forming metals is especially important in the case of abundant agricultural biomass due to their typically high ash contents and high alkali and alkaline earth metal (AAEM) contents. Fig. 2 shows the removal rates of these troublesome elements by washing with DW, AA and CA. In general, the light metals are easily removed (higher than $72 \%$ ) and the removal rates are similar with each tested washing agents. For example, the highest and lowest removal rates of Mg from PCF were 92\% (CA washing) and 81\% (DW washing), respectively. As for removal rates of $\mathrm{Mg}$ from PPW, they are 93 and $75 \%$ achieved by CA and DW washing, respectively. With regard to the two light metals of greatest concern, $\mathrm{K}$ and $\mathrm{Na}$, the type of washing agent used plays a minor role, as they can be efficiently removed by all the tested washing agents. The removal rates of Na from PCF by washing with DW, AA and CA are 96.5, 97 and 97\%, respectively, and in the case of $K$, they are 93, 93 and $96 \%$ by washing with DW, AA and $\mathrm{CA}$, respectively. These observations are in agreement with the previous reports that water washing can remove high fraction of $\mathrm{K}$ and $\mathrm{Na}$ originally contained in biomass [10,15,19]. For example, it was reported that up to $92 \%$ of $\mathrm{Na}$ and $62 \%$ of $\mathrm{K}$ were removed from raw herbaceous biomass by water washing [15].

Compared to light metals, heavy metals show relatively lower removal rates by tested washing agents. For example, the removal rates of Si in PPW and PCF are lower than 65 and 62\%, respectively. In the case of Fe, the highest removal rates from PCF and PPW were only $88 \%$ and $89 \%$ achieved by CA washing treatment, respectively. In addition, the acid washing agents (AA and CA) show higher removal capacities than DW, and CA exhibits the highest removal rates among all tested washing agents. As an example, the removal rates of $\mathrm{Al}$ in PCF were 58,81 and $83 \%$ achieved by washing with DW, AA and CA, respectively. And the lowest removal rate of $\mathrm{Al}$ in PPW (only around 54\%) is also achieved by washing with DW.

The different removal rates for light and heavy metals are possibly associated with their different chemical forms in the biochars. Light metals such as $\mathrm{K}$ and $\mathrm{Na}$, occur in the form of water soluble materials in raw biomass, and thus can be efficiently removed by water washing $[10,15,19]$. However, substantial amount of heavy metals such as Fe and Ti are known to exist as oxyhydroxides and silicates in raw biomass, and some heavy metals are present in the form of crystal inorganics [22]. These compounds have higher solubility in acid solutions than in DW, thereby resulting in higher removal rates by acid washing in the present study.

When comparing two tested acid washing agents, CA shows higher metal removal capacity from both PCF and PPW than AA, well consistent with the lower ash content of PCF-CA and PPW-CA. The higher removal rates are mainly associated with the higher acidity and more co-ordination sites of CA. As we know, heavy metal ions are present in three forms when washed by AA and CA: 1) free ions in the solution; 2) physical adsorption onto the surface of the biochars and 3) co-ordination with carboxyl groups of AA and CA [7,18,23,24]. Compared to physical adsorption, heavy metals tend to co-ordinate with carboxyl groups when more co-ordination sites are available due to the higher stability of co-ordination. CA has more co-ordination sites than AA; therefore, more metal ions enter into solution by coordinating with carboxyl groups, resulting in higher removal rates. Moreover, more metals are converted into aqueous soluble phase due to the higher acidity of $C A\left(\mathrm{pK}_{1}(\mathrm{AA})=4.76\right.$ and $\left.\mathrm{pK}_{1}(\mathrm{CA})=3.13\right)$, which contributes to higher removal rates. 


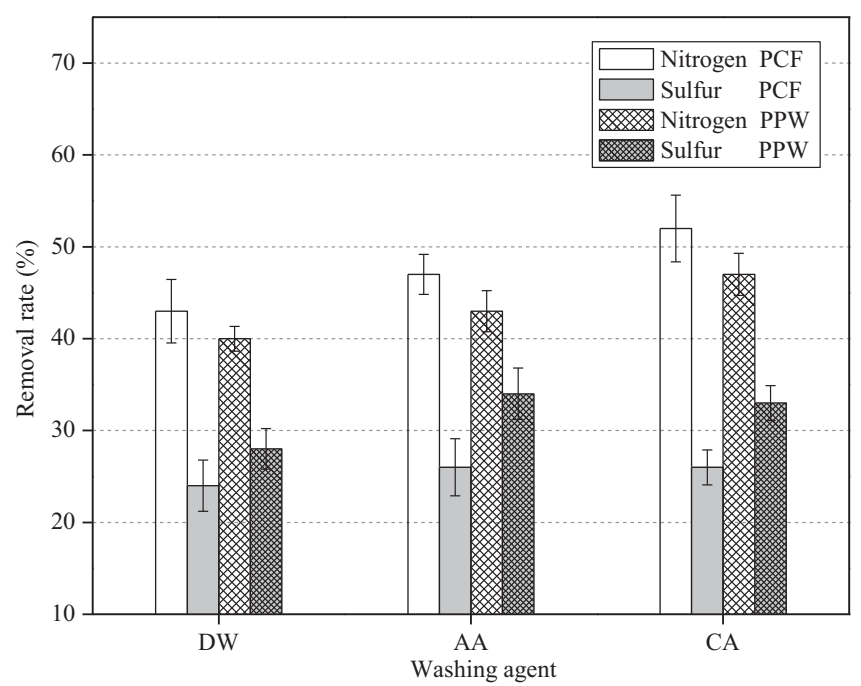

Fig. 3. Removal rates of nitrogen and sulfur from the biochars by different washing agents.

\subsection{Sulfur and nitrogen}

Nitrogen and sulfur contents are also a key concern for solid fuels because they could be transformed into $\mathrm{NO}_{\mathrm{x}}$ and $\mathrm{SO}_{2}$ in the subsequent combustion process. As shown in Fig. 3, the contents of nitrogen and sulfur in washed biochars are noticeably decreased compared to untreated biochars. In general, the removal rates of nitrogen and sulfur are higher than $40 \%$ and $24 \%$, respectively. The highest removal rates of nitrogen and sulfur are 52 and 26\% from PCF and 47 and 34\% from PPW, respectively. In addition, though less pronounced, the acid washing agents show higher nitrogen and sulfur removal rate from the biochars than DW. The decreased nitrogen and sulfur contents imply that greater environmental benefits can be achieved by use of washed biochars compared to untreated biochars [25].

\subsection{Slagging and fouling issues}

Table 3 presents the contents of metal oxides related to ash problems in the ashes of untreated and washed biochars. It can be seen that the ash of washed biochars have decreased contents of AAEM oxides in comparison to the ash of untreated biochars, which is consistent with the relatively high removal rates of AAEMs in above metal removal analysis.

The slagging and fouling inclinations of the biochars were determined before and after washing treatment. As shown in Table 3, there is a significant decrease for the slagging and fouling inclination for both PCF and PPW after washing treatment due to decreased contents of AAEM oxides in comparison to untreated biochars. The slagging index (SI) value, 0.76 , indicates that PCF has medium slagging formation potential when it is combusted (the acceptable range for low slagging inclination SI $<0.60$ (shown in Table 2)). The SI value decreases to $0.08,0.07$ and 0.07 after washing by DW, AA and CA, respectively, which are in the range of low slagging inclination. Due to its low AAEM oxide contents, PPW has a lower SI value (0.28). Washing with DW, AA and CA further decreases SI to $0.08,0.03$ and 0.03 , respectively.

As we know, compared to woody biomass, agro-residues suffer from serious slagging problems due to high AAEM contents. In this study, it is shown that washing treatments address the slagging problem, such that biochars derived from woody biomass and agro-residues have similar slagging inclination. In addition, the increased slagging viscosity confirms the mitigated slagging issue by washing treatment. With respect to fouling index, PCF and PPW occur in high and medium fouling ranges, respectively. Significant decreases for fouling index (FI) values of PCF are observed after washing treatment; however, its values still are in the medium fouling range. As for PPW, its FI decreases from medium to low inclination range by washing treatment (from 7.40 to $0.39,0.14$ and 0.23 by washing with DW, AA and CA respectively). When comparing different washing agents, only small differences in slagging and fouling indices are observed.

\subsection{Combustion characteristics}

The differential thermal gravimetric (DTG) profiles depicting the combustion process of untreated biochar and washed biochars are presented in Fig. 4. The characteristic temperatures and peak points of the combustion process are summarized in Table 4.

As shown in Fig. 4, the washing treatment exerts stronger effects on the combustion behavior of PCF compared to PPW. The washed PCF biochars exhibited totally different DTG curve patterns compared to untreated biochar, especially for the biochar PCF-CA and PCF-AA. Considering that the temperature at which the maximum weight loss rate occurs is inversely proportional to the reactivity, it is clear that the washing treatments significantly decreased the reactivity of the PCF biochar [7]. The combustion of unwashed PCF occurs in two separated temperature zones: from 274 to $313^{\circ} \mathrm{C}$ and 313 to $422^{\circ} \mathrm{C}$ centered at around 286 and $400{ }^{\circ} \mathrm{C}$, respectively. Moreover, the main weight loss (around $39.53 \%$ ) takes place at a low temperature zone during PCF combustion. This low temperature for the main weight loss, and the separated combustion zones, implies low thermal efficiency of PCF combustion. In contrast, only one main DTG curve is observed for PCF-DW, centered at $391{ }^{\circ} \mathrm{C}$ (one minor shoulder peak is also present). By comparing with the DTG curve of PCF, it can be seen that the low combustion zone disappeared and the main weight loss shifted to a higher combustion zone of $298-442{ }^{\circ} \mathrm{C}$ during PCF-DW combustion. The sharply decreased reactivity of PCF-DW is mainly ascribed to the removal of AAEMs originally contained in PCF, which are reported to serve as catalysts for biomass pyrolysis $[15,26]$. In the case of PCF-AA and PCF-CA, similar combustion

Table 3

Major metal oxides and slagging/fouling indices in the ashes of untreated biochars and washed biochars, \%.

\begin{tabular}{|c|c|c|c|c|c|c|c|c|}
\hline & PCF & PCF-DW & PCF-AA & PCF-CA & PPW & PPW-DW & PPW-AA & PPW-CA \\
\hline $\mathrm{K}_{2} \mathrm{O}$ & 49.24 & 11.50 & 15.38 & 12.06 & 7.51 & 1.15 & 0.99 & 1.45 \\
\hline $\mathrm{CaO}$ & 10.40 & 8.01 & 3.36 & 5.04 & 23.11 & 12.06 & 4.72 & 5.40 \\
\hline $\mathrm{Na}_{2} \mathrm{O}$ & 3.43 & 0.33 & 0.45 & 0.62 & 1.40 & 0.08 & 0.12 & 0.20 \\
\hline $\mathrm{MgO}$ & 2.26 & 1.42 & 0.82 & 1.15 & 4.48 & 2.14 & 1.46 & 1.48 \\
\hline $\mathrm{Fe}_{2} \mathrm{O}_{3}$ & 0.54 & 1.05 & 0.45 & 0.42 & 6.55 & 7.55 & 3.20 & 3.44 \\
\hline $\mathrm{Al}_{2} \mathrm{O}_{3}$ & 0.24 & 0.32 & 0.20 & 0.22 & 3.10 & 2.70 & 1.81 & 2.39 \\
\hline $\mathrm{TiO}_{2}$ & 0.27 & 0.50 & 0.51 & 0.79 & - & - & - & - \\
\hline $\mathrm{SiO}_{2}$ & 31.83 & 75.18 & 77.34 & 77.96 & 48.75 & 68.99 & 82.56 & 81.54 \\
\hline $\mathrm{B} / \mathrm{A}$ & 2.04 & 0.29 & 0.26 & 0.24 & 0.83 & 0.32 & 0.12 & 0.14 \\
\hline SI & 0.76 & 0.08 & 0.07 & 0.07 & 0.28 & 0.08 & 0.03 & 0.03 \\
\hline FI & 107.94 & 3.47 & 4.15 & 3.10 & 7.40 & 0.39 & 0.14 & 0.23 \\
\hline SVI & 70.69 & 87.77 & 94.35 & 92.18 & 58.81 & 76.03 & 89.80 & 88.75 \\
\hline
\end{tabular}

- Not available. 

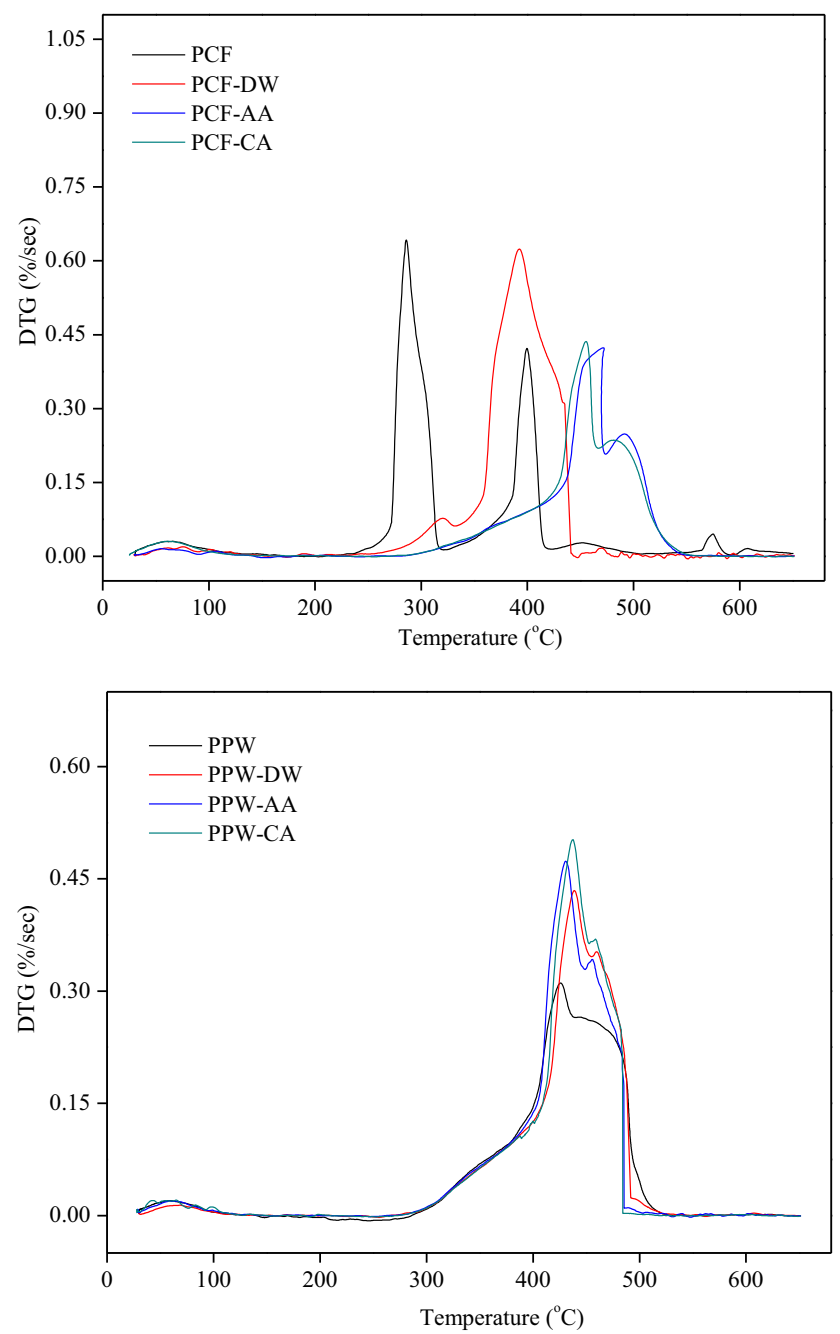

Fig. 4. DTG curves of the washed biochars. The washing biochars with different washing agents.

pattern was observed generally, confirming that AA and CA have similar metal removal capacities from PCF. Compared to PCF-DW, the reactivities of PCF-AA and PCF-CA were further decreased, and the combustion temperatures further shifted to higher values, $303-543{ }^{\circ} \mathrm{C}$ for PCF-AA and $303-542{ }^{\circ} \mathrm{C}$ for PCF-CA, respectively. In addition, the reactivity of the PCF-CA was slightly higher than that of PCF-AA, which is ascribed to the decrease in heavy metal contents. In addition, one minor peak centered around $575{ }^{\circ} \mathrm{C}$ is clearly observed in PCF curve, which is

Table 4

Combustion parameters of untreated biochars and corresponding washed biochars.

\begin{tabular}{llllllll}
\hline Fuel & $\begin{array}{l}\mathrm{Ti}^{\mathrm{a}} \\
\left({ }^{\circ} \mathrm{C}\right)\end{array}$ & \multicolumn{2}{l}{ Combustion zone } & & $\begin{array}{l}\mathrm{T}_{\mathrm{b}} \\
\left({ }^{\circ} \mathrm{C}\right)\end{array}$ & $\begin{array}{l}\text { Total } \\
\text { burnout }(\%)\end{array}$ \\
\cline { 3 - 6 } & & $\begin{array}{l}\text { Temp. } \\
\text { range }\left({ }^{\circ} \mathrm{C}\right)\end{array}$ & $\begin{array}{l}\mathrm{T}_{\text {peak }} \\
\left({ }^{\circ} \mathrm{C}\right)\end{array}$ & $\begin{array}{l}\mathrm{R}_{\max } \\
(\% / \mathrm{s})\end{array}$ & $\begin{array}{l}\text { Weight } \\
\text { loss }(\%)\end{array}$ & & \\
\hline PCF & 274 & $274-313$ & 286 & 0.64 & 39.53 & 422 & 90.05 \\
& - & $313-422$ & 400 & 0.42 & 31.38 & & \\
PCF-DW & 298 & $298-442$ & 391 & 0.62 & 89.83 & 442 & 96.94 \\
PCF-AA & 303 & $303-543$ & 470 & 0.42 & 93.14 & 543 & 97.79 \\
PCF-CA & 303 & $303-542$ & 456 & 0.43 & 91.18 & 542 & 98.38 \\
PPW & 338 & $338-499$ & 426 & 0.31 & 90.04 & 499 & 97.48 \\
PPW-DW & 340 & $340-498$ & 439 & 0.43 & 95.28 & 498 & 98.74 \\
PPW-AA & 340 & $340-487$ & 431 & 0.47 & 94.30 & 487 & 99.25 \\
PPW-CA & 340 & $340-482$ & 437 & 0.50 & 93.80 & 482 & 99.39 \\
\hline
\end{tabular}

- Not available.

a $T_{i}=$ ignition temperature; $T_{b}=$ burnout temperature. ascribed to the decomposition of inorganic components in the ash [7]. Due to the decreased ash contents, this peak disappeared after DW, $\mathrm{AA}$ and $\mathrm{CA}$ washing.

In the case of PPW, smaller differences of DTG curves are observed by washing treatments compared to PCF. This is ascribed to the overall low metal content in PPW, especially for AAEMs. Due to decreased heavy metal content, PPW-DW, PPW-AA and PPW-CA have slightly increased reactivity compared to PPW. In addition, the total burnouts of washed biochars are increased compared to untreated biochars, in agreement with the ash content analysis.

In comparison with woody biomass, the most abundant agroresidues are more difficult to use, due to their low fuel quality [27]. As shown in Fig. 4, the combustion pattern of agro-residue derived PCF is very different from that of PPW derived from woody biomass with respect to combustion temperature and reactivity. However, the acid washed PCF and PPW show similar combustion behavior, indicating that acid washing can reduce the differences between agro-residues and woody biomass. Therefore, acid washing treatment could enable co-firing of low quality agro-residue derived biochars with coal in existing coal-fired systems, without requiring major modifications.

\section{Conclusions}

Washing treatment significantly improved fuel qualities of pyrolytic biochars derived from both woody and agricultural biomass. Higher than $72 \%$ of alkali and alkaline earth metals were removed by all tested washing agents. In the case of heavy metals, the acid washing agent tested showed higher removal capacity than water, especially citric acid. As a consequence, the ash-related problems of the biochars are significantly mitigated and combustion behavior is remarkably improved, especially for the biochars derived from agricultural biomass. In addition, enhanced environmental benefits can be achieved by use of washed biochars due to decreased nitrogen and sulfur contents.

Compared to raw biomass washing, biochar washing has increased washing efficiency and decreased energy consumption indicated by low hydrophilicity of the biochars. Therefore, the present study demonstrated that low temperature pyrolysis combined with washing treatment provides a promising option to produce solid fuel biochars with high fuel quality from both woody and agricultural biomass economically.

\section{Acknowledgement}

Financial support from the Chinese Academy of Sciences is greatly acknowledged.

\section{References}

[1] S.K. Hoekman, A. Broch, C. Robbins, Hydrothermal carbonization (HTC) of lignocellulosic biomass, Energy and Fuels 25 (2011) 1802-1810.

[2] R.D. Perlack, L.L. Wright, A.F. Turhollow, R.L. Graham, B.J. Stokes, D.C. Erbach, Biomass as Feedstock for Bioenergy and Bioproducts Industry: The Technical Feasibility of a Billion-ton Annual Supply, Oak Ridge National Laboratory, Oak Ridge, TN, 2005.

[3] R. Saidur, E.A. Abdelaziz, A. Demirbas, M.S. Hossain, S. Mekhilef, A review on biomass as a fuel for boilers, Renewable and Sustainable Energy Reviews 15 (2011) 2262-2289.

[4] J. Dai, S. Sokhansnji, J.R. Grace, X. Bi, C.J. Kim, S. Melin, Overview and some issues related to co-firing biomass and coal, Canadian Journal of Chemical Engineering 86 (2008) 367-386.

[5] H. Abdullah, H. Wu, Biochars as a fuel: 1. Properties and grindability of biochars produced from the pyrolysis of mallee wood under slow-heating conditions, Energy and Fuels 23 (2009) 4174-4181.

[6] M. Phanphanich, S. Mani, Impact of torrefaction on the grindability and fuel characteristics of forest biomass, Bioresource Technology 102 (2011) 1246-1253.

[7] Z. Liu, R. Balasubramanian, A comparison of thermal behaviors of raw biomass, pyrolytic biochar and their blends with lignite, Bioresource Technology 146 (2013) 371-378.

[8] Z. Liu, R. Balasubramanian, A comparison of nitrogen conversion during pyrolysis of coconut fiber, its corresponding biochar and their blends with lignite, Bioresource Technology 151 (2014) 85-90. 
[9] Z. Liu, R. Balasubramanian, Upgrading of waste biomass by hydrothermal carbonization (HTC) and low temperature pyrolysis (LTP): a comparative evaluation, Applied Energy 114 (2014) 857-864.

[10] M.A. Carrillo, S.A. Staggenborg, J.A. Pineda, Washing sorghum biomass with water to improve its quality for combustion, Fuel 116 (2014) 427-431.

[11] K.O. Davidsson, J.G. Koresgren, J.B.C. Pettersson, U. Jaglid, The effects of fuel washing techniques on alkali release from biomass, Fuel 81 (2002) 137-142.

[12] L. Deng, T. Zhang, D. Che, Effect of water washing on fuel properties, pyrolysis and combustion characteristics, and ash fusibility of biomass, Fuel Processing Technology 106 (2013) 712-720.

[13] B.M. Jenkins, R.R. Bakker, J.B. Wei, On the properties of washed straw, Biomass and Bioenergy 10 (1996) 177-200.

[14] P.A. Jensen, B. Sander, K. Dam-Johansen, Pretreatment of straw for power production by pyrolysis and char wash, Biomass and Bioenergy 20 (2001) 431-446.

15] A. Saddawi, J.M. Jones, A. Williams, C.L. Coeur, Commodity fuels from biomass through pretreatment and torrefaction: effects of mineral content on torrefied fuel characteristics and quality, Energy and Fuels 26 (2012) 6466-6474.

[16] N. Said, T. Bishara, A. Garcia-Maraver, M. Zamorano, Effect of water washing on the thermal behavior of rice straw, Waste Management 33 (2013) 2250-2256.

[17] M.J.C. Van der Stelt, H. Gerhauser, J.H.A. Kiel, K.J. Ptasinski, Biomass upgrading by torrefaction for the production of biofuels: a review, Biomass and Bioenergy 35 (2011) 3748-3762.

[18] Z. Liu, F.S. Zhang, J. Wu, Characterization and application of char produced from pinewood pyrolysis and hydrothermal treatment, Fuel 89 (2010) 510-514.
[19] P.A. Jensen, B. Sander, K. Dam-Johansen, Removal of $\mathrm{K}$ and $\mathrm{Cl}$ by leaching of straw char, Biomass and Bioenergy 20 (2001) 447-457.

[20] C. Yu, P. Thy, L. Wang, S.N. Anderson, J.S. VanderGheynst, S.K. Upadhyaya, B.M. Jenkins, Influence of leaching pretreatment on fuel properties of biomass, Fuel Processing Technology 128 (2014) 43-53.

[21] M. Pronobis, Evaluation of the influence of biomass co-combustion on boiler furnace slagging by means of fusibility correlations, Biomass and Bioenergy 28 (2005) 375-383.

[22] S.V. Vassilev, D. Baxter, L.K. Andersen, C.G. Vassileva, T.J. Morgan, An overview of the organic and inorganic phase composition of biomass, Fuel 94 (2012) 1-33.

[23] X. Dong, L. Ma, Y. Li, Characterization and mechanisms of hexavalent chromium removal by biochar from sugar beet tailing, Journal of Hazardous Materials 190 (2011) 909-915.

[24] D. Kolodynsha, R. Wnetrzak, J.J. Leahy, M.H.B. Hayes, W.K. Wapinski, Z. Hubicki, Kinetic and adsorptive characterization of biochar in metal ions removal, Chemical Engineering Journal 197 (2012) 295-305.

[25] A.A. Khan, W. Jong, P.J. Jansens, H. Spliethoff, Biomass combustion in fluidized bed boilers: potential problems and remedies, Fuel Processing Technology 90 (2009) 21-50.

[26] K. Raveendran, A. Ganesh, K.C. Khilar, Influence of mineral matter on biomass pyrolysis characteristics, Fuel 74 (1995) 1812-1822.

[27] Z. Liu, A. Quek, R. Balasubramanian, Preparation and characterization of fuel pellets from woody biomass, agro-residues and their corresponding hydrochars, Applied Energy 113 (2014) 1315-1322. 